\title{
Injury of epigastric vessels at laparoscopy: diagnosis and management
}

\author{
Philippe de Rosnay • Manju Chandiramani • \\ Sana Usman • Elizabeth Owen
}

Received: 29 October 2010 / Accepted: 17 December 2010/Published online: 11 January 2011

(C) Springer-Verlag 2011

Keywords Epigastric vessel injury - Operative laparoscopy

\section{Introduction}

The abdominal wall has an abundant vasculature which is particularly susceptible to injury at laparoscopic surgery [1]. The most commonly injured vessels in laparoscopic procedures are the epigastric arteries, both the superficial and deeper vessels $[2,3]$. As early as 1823 , injury to the epigastric vessels during surgery was recognised [4]. We present two different manifestations of inferior epigastric vessel injury at laparoscopic surgery and how they were managed.

\section{Case presentation}

Case A

A 26-year-old woman underwent laparoscopy for chronic pelvic pain. The primary trocar $(10 \mathrm{~mm})$ was inserted intraumbilically, and a $5-\mathrm{mm}$ port was placed in the left iliac fossa under direct vision. A small amount of bleeding into the peritoneal cavity was noted from this port site, and an additional 5-mm port was placed in the right iliac fossa to facilitate further instrumentation. The bleeding point was

P. de Rosnay $(\varangle) \cdot$ M. Chandiramani $\cdot$ S. Usman $\cdot$ E. Owen

Department of Obstetrics and Gynaecology,

West Middlesex University Hospital NHS Trust,

Twickenham Road,

Isleworth, Middlesex TW7 6AF, UK

e-mail: docphilippe@hotmail.com coagulated using bipolar electrocoagulation with apparent good effect. The patient was noted to have filmy pelvic adhesions, but no significant cause was found for the pain. There were no immediate postoperative concerns, and she was discharged home the same day. Six days later, she presented to the accident and emergency department with lower abdominal pain, voiding difficulty and fever. Her haemoglobin level had fallen from $13.3 \mathrm{~g} / \mathrm{dL}$ preoperatively to $10.4 \mathrm{~g} / \mathrm{dL}$ postoperatively. An infected pelvic collection was suspected, and broad-spectrum antibiotics administered intravenously were commenced. An ultrasound scan of her abdomen (Fig. 1), however, confirmed a large haematoma, measuring $10.1 \times 7.7 \times 4.0 \mathrm{~cm}$ between the rectus sheath and peritoneum. As there was no significant fluid component amenable to drainage, she was managed conservatively, and a follow-up ultrasound scan 6 weeks later showed a reduction in the size of the haematoma to $5.9 \times 5.3 \times$ $4.6 \mathrm{~cm}$. She complained of bladder symptoms for several weeks, but eventually, her symptoms resolved completely, and further imaging showed complete resolution of the haematoma.

\section{Case B}

A 48-year-old woman of Polish origin with a history of lower abdominal pain and a pelvic mass was referred by her general practitioner. She previously had emergency surgery for a ruptured appendix. Abdominal examination revealed a longitudinal paraumbilical scar with a small incisional hernia. A pelvic ultrasound scan showed a left-sided ovarian cyst, measuring $8.4 \times 7.1 \times 6.1 \mathrm{~cm}$, with no complex features. Tumour markers were normal. At operation, the laparoscope was introduced through a $10-\mathrm{mm}$ intraumbilical incision. Two additional 5-mm ports were inserted in 


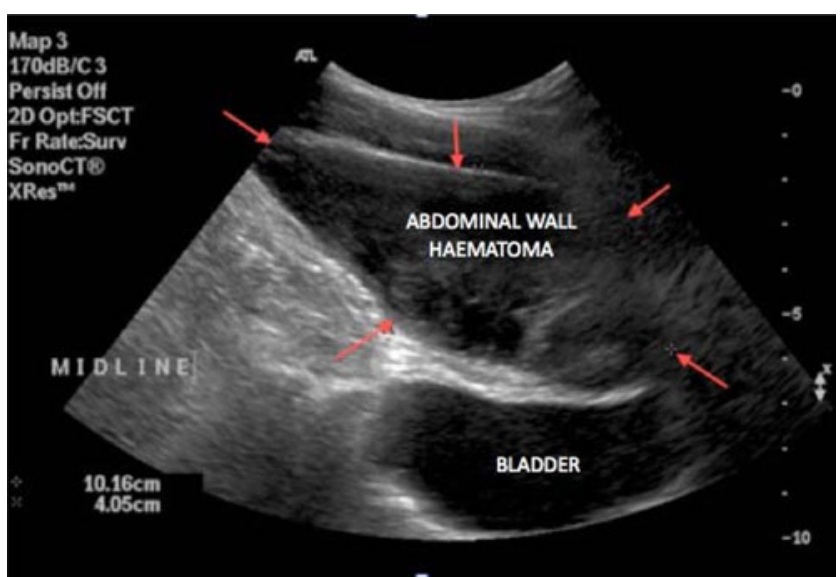

Fig. 1 Transabdominal ultrasound scan showing a large haematoma in the anterior abdominal wall $(10.1 \times 7.7 \times 4.0 \mathrm{~cm})$

the left and right iliac fossae under direct laparoscopic vision. A left oophorectomy was performed using 'tripolar' coagulation shears, and the specimen was removed through the $10-\mathrm{mm}$ umbilical port using a laparoscopic tissue retrieval 'Endocatch' (Cory Bros, Shenley, Hertfordshire) bag. This was done under direct vision with a 5-mm laparoscope, inserted through the right iliac fossa port. At the end of the procedure, the ports were removed under direct vision, with release of carbon dioxide. Monofilament sutures were used for skin closure.

She was initially observed in the recovery area and, subsequently, transferred to the day surgical ward. One hour postoperatively, nursing staff noted bleeding from the port site in the right iliac fossa. On review by the registrar, a subcutaneous haematoma was noted with blood 'oozing' from the port site. A pressure dressing was applied. Subsequent review by the team consultant noted that the haematoma was increasing in size. Two interrupted abdominal wall sutures were placed just inferior to the port site, as bleeding from the inferior epigastric artery was suspected. A full blood count revealed a haemoglobin level of $9.9 \mathrm{~g} / \mathrm{dL}(12.1 \mathrm{~g} / \mathrm{dL}$ preoperatively). The bleeding from the port site settled, but she remained in the hospital overnight for observation. The following day, she was noted to have a $4-\mathrm{cm}$ haematoma in the right iliac fossa, with no obvious active bleeding. A further pressure dressing was applied, and she was discharged home with a planned review 2 days later.

She presented the following day to the accident and emergency department with widespread bruising across her lower abdomen and right thigh (Fig. 2). An ultrasound scan confirmed diffuse superficial soft tissue oedema in the absence of a drainable collection. The haemoglobin level was noted to have dropped to $7.3 \mathrm{~g} / \mathrm{dL}$. The option of blood transfusion was discussed, but as she was clinically stable, a

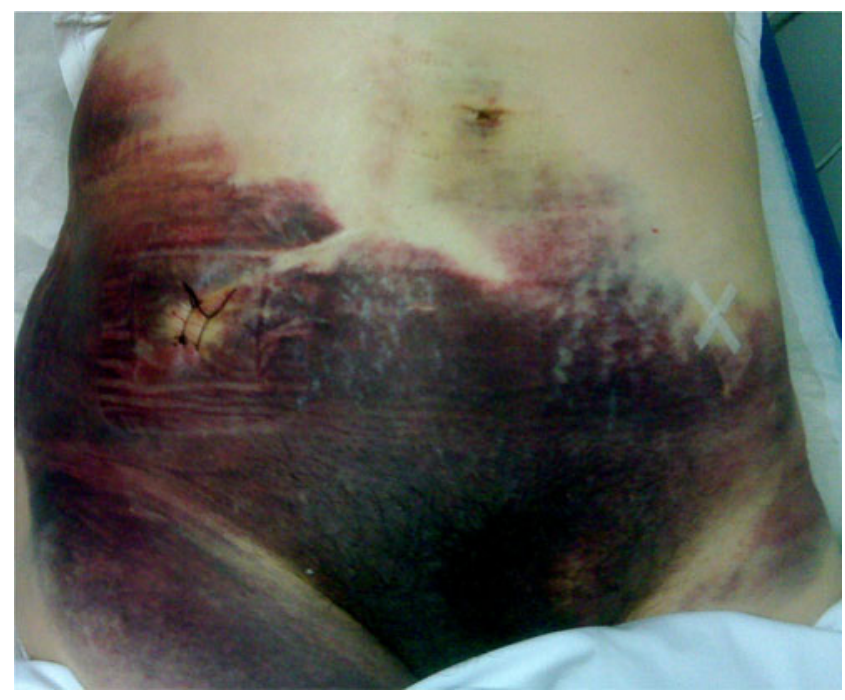

Fig. 2 Widespread bruising across the lower abdomen and right thigh following epigastric vessel injury

decision was made to withhold transfusion. She was commenced on broad-spectrum antibiotics and iron supplementation administered per os with the view to expectant management. She was followed up over a 2-month period, and there was gradual but complete resolution of the bruising.

\section{Discussion}

Injury to the inferior epigastric vessels is relatively uncommon but may occur in up to $2 \%$ of operative laparoscopic procedures during insertion of lateral trocars [1]. The injury can occur with the initial insertion of a sharp trocar directly into the vessels or later in the procedure when the incision is widened to allow passage of a larger cannula or for removal of tissue from the peritoneal cavity. One could argue that inferior epigastric vessel injury should never occur with accessory ports if they are placed under direct laparoscopic vision. However, distortion of the anterior abdominal wall anatomy, for example, from previous surgery or inadvertently introducing trocars at an angle (instead of perpendicular to the skin) may predispose to injury.

The degree of injury can vary, ranging from mild, such as a small amount of blood dripping into the operative field [5], as in case A, superficial bruising which may be extensive (case B), to more severe injury resulting in severe life-threatening haemorrhage (requiring transfusion), haematoma or abscess formation, as well as further operations to achieve haemostasis [6-9]. Knowledge of the anatomy of the epigastric vessels and correct trocar placement (under direct vision) to avoid injury are as important as managing injury quickly to avoid major complications. 
The inferior epigastric artery is a branch of the external iliac artery with its origin just above the inguinal ligament. It courses superiorly and medially towards the umbilicus. It lies just medial to the round ligament as the ligament passes through the deep inguinal ring into the inguinal canal and lateral to the obliterated umbilical vessels (Fig. 3). It pierces the fascia transversalis to enter the rectus sheath anterior to the arcuate line. It ascends behind the rectus muscle, supplying the lower central part of the anterior abdominal wall, and anastomoses with the superior epigastric artery [10].

The superficial epigastric vessels originate from the femoral artery just below the inguinal ligament. They pass through the saphenous opening in the fascia lata and ascend onto the abdomen in the superficial fascia covering the external oblique muscle. The vessels ascend almost to the level of the umbilicus [11]. It is good practice to visualise the superficial abdominal wall vessels by transillumination, although this can often be difficult in dark-skinned and obese women [12]. Superficial epigastric vessel damage usually heals with expectant management, and rotation of the cannula to a position at which compression is maximal may be helpful [5]. Occasionally, sutures may be required to stem the bleeding.

Hurd et al. [13] and Saber et al. [1] used CT scans to determine vessel location in relation to anatomical landmarks, and therefore, recommended an entry point $5 \mathrm{~cm}$ superior to the pubic symphysis and $8 \mathrm{~cm}$ from the midline. In a recent study which dissected the ilioinguinal and iliohypogastric nerves and the inferior epigastric vessels in 11 unembalmed female cadavers, the inferior epigastric vessels were $3.7 \mathrm{~cm}(2.6-5.5 \mathrm{~cm})$ from the midline at the level of the anterior superior iliac spine and always lateral

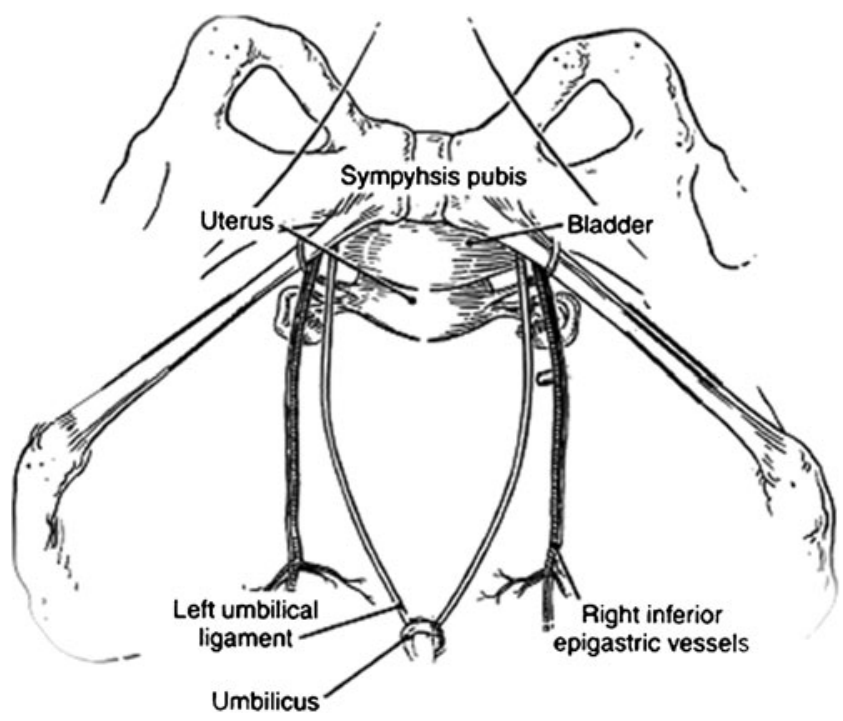

Fig. 3 Anterior abdominal wall structures and safe laparoscopic entry (Adapted from Nezhat [23]) to the rectus muscles at a level $2 \mathrm{~cm}$ superior to the pubic symphysis [14].

Direct visualisation transperitoneally is the ideal approach to avoid inferior epigastric vessel injury during laparoscopic accessory trocar placement, which should be inserted lateral to the vessels at a $90^{\circ}$ angle to the abdominal wall. Where it is not possible to visualise the vessels, for example in obese patients, methods of transillumination and surface landmarks are often relied on. Recent data suggest that the risk of nerve and vessel injury may be minimised when lateral trocars are placed superior to the anterior superior iliac spines and $>6 \mathrm{~cm}$ from the midline [14]. Handheld Dopplers have been used in difficult cases to effectively identify the inferior epigastric arteries [15].

Hurd et al. [7] looked at the size and shape of the trocar used and compared the risk of abdominal wall vessel injury in an animal model. When the vessel was directly punctured at its midpoint, there were no differences in outcome. However, if the vessel wall was injured at its periphery, there was a greater likelihood of laceration and bleeding if a large-diameter pyramidal trocar was used [16]. Reduction in the risk of vessel injury can also be achieved by placement of smaller trocars laterally, with larger trocars remaining in the midline where possible. Ternamian et al. reported on more than 4,000 women undergoing laparoscopic surgery using Endo TIP trocarless threaded cannulae. In these women, no abdominal wall injury was encountered in more than 10,000 insertions of 5-mm secondary trocarless cannulae [17]. Insertion of lateral ports should be perpendicular to the skin, and only when the peritoneal membrane is breached should the trocar be directed, so as to avoid the pelvic sidewall and other vital structures.

Recognition of vessel injury may be achieved by observing blood dripping down the cannula, abdominal wall discoloration or development of a haematoma around or near the incision. In some instances, the blood may track to a more distant site, manifesting as a pararectal or vulval mass [5]. It is advisable to directly visualise the removal of accessory trocars, as this may reveal inadvertent bleeding points.

A number of techniques have been described to manage intractable bleeding from inferior epigastric vessels [7, 12, 18-20]. Coagulation is sometimes successful, but this should be used with caution, as bleeding vessels may retract from the peritoneal surface, giving a false impression of haemostasis, as illustrated in case A. A Foley catheter may be inserted through the port site, and the balloon inflated in the peritoneal cavity. The balloon can then be pulled up against the bleeding point with a resultant tamponade effect. The catheter can be secured externally using a clamp. Some clinicians suggest leaving this in situ for $24 \mathrm{~h}$, but there have been reports that the clamp could 
damage the channel in the catheter, making it impossible to deflate the balloon [5]. Lacerated inferior epigastric vessels should ideally be ligated. The use of a modified, straight ligature carrier is useful. The suture should be placed under direct laparoscopic vision inferior to the area of concern, as well as on both sides of the bleeding vessel. Placing deep mattress sutures can also be attempted, with the sutures usually removed about $48 \mathrm{~h}$ later [5]. The use of percutaneous, selective, left external iliac and left inferior epigastric angiography, followed by embolisation with platinum microcoils and polyvinyl alcohol has also been described to arrest bleeding at operative laparoscopy with good success and may be employed in institutions where this is readily available [12].

Bleeding may not immediately be apparent to the surgical team due to a number of factors, including increased abdominal pressure (pneumoperitoneum) or decreased venous pressure associated with the Trendelenburg position [21]. If the lacerated vessel presents postoperatively as a haematoma, initial management should be with local compression. The temptation to open or aspirate the haematoma should be resisted, as such a manoeuvre may inhibit the tamponade effect and could increase the risk of abscess formation. If the haematoma continues to enlarge, however, or if there is evidence of haemodynamic compromise, wound exploration is indicated [22].

\section{Conclusion}

Although some of the issues highlighted in this report are not necessarily new, they serve as a timely reminder to all clinicians involved in laparoscopic surgery. A thorough understanding of the anterior abdominal wall anatomy and prevention of vessel injury through sound technique are crucial. When vessel injury does occur, however, a strategy for recognising and minimising inadvertent complications is important when undertaking safe operative laparoscopy.

Declaration of interest The authors report no conflicts of interest. The authors alone are responsible for the content and writing of the paper.

\section{References}

1. Saber AA, Meslemani AM, Davis R et al (2004) Safety zones for anterior abdominal wall entry during laparoscopy: a CT scan mapping of epigastric vessels. Am Surg 239:182-185

2. Lin P (1999) Complications of laparoscopy: strategies for prevention and cure. Obstet Gynecol Clin North Am 26:23-38
3. Colborn GL, Sleandalakis J (1995) Laparoscopic cadaveric anatomy of the inguinal area. Probl Gen Surg 12:13

4. Bogros AJ (1823) Esai sur l'anatomie chirurgical de la region iliaque et description d'un nouveau procede pour feure la ligature des arteres epigastrique et iliaque extreme (thesis). Paris. Didot Le Jeune; no. 153

5. Munro MG (2006) Complications of laparoscopic access. In: Isaacson K (ed) Gynecologic endoscopic surgery, 1st edn. Elsevier, Philadelphia, pp 59-60

6. Bergqvist D, Bergqvist A (1987) Vascular injuries during gynaecological surgery. Acta Obstet Gynecol Scand 66:19-23

7. Hurd WW, Pearl MM, DeLancey JO et al (1993) Laparoscopic injury of abdominal wall vessels: a report of three cases. Obstet Gynecol 82:673-676

8. Todd AW (2001) Inadvertent puncture of the inferior epigastric artery during needle biopsy with fatal outcome. Clin Radiol 56:989-1002

9. Lam EY, McLafferty RB, Taylor LM Jr et al (1998) Inferior epigastric artery pseudoaneurysm: a complication of paracentesis. J Vasc Surg 28:566-569

10. Snell RS (1995) Clinical anatomy for medical students, 5th edn. Little, Brown and Company Inc., United States, p 144

11. Williams P, Dyson M (1989) Gray's anatomy, 37th edn. Churchill Livingstone, Edinburgh, p 782

12. Lavery S, Porter S, Trew G et al (2006) Use of inferior epigastric artery embolization to arrest bleeding at operative laparoscopy. Fertil Steril 86(719):e13-e14

13. Hurd WW, Bude RO, DeLancey JOL et al (1994) The location of abdominal wall blood vessels in relationship to abdominal landmarks apparent at laparoscopy. Am J Obstet Gynecol 171:642-646

14. Rahn DD, Phelan JN, Roshanravan SM et al (2010) Anterior abdominal wall nerve and vessel anatomy: clinical implications for gynaecologic surgery. Am J Obstet Gynecol 202(234):e1e5

15. Whiteley MS, Laws SA, Wise MH (1994) Use of hand-held Doppler to avoid abdominal wall vessels in laparoscopic surgery. Ann R Coll Surg Engl 76:348-350

16. Hurd WW, Wang L, Schemmel MT (1995) A comparison of the relative risk of vessel injury with conical versus pyramidal laparoscopic trocars in a rabbit model. Am J Obstet Gynecol 173:1731-1733

17. Ternamian AM, Vilos GA, Vilos AG et al (2010) Laparoscopic peritoneal entry with the reusable threaded visual cannula. J MIG $17: 461-467$

18. Chatzipapas IK, Magos AL (1997) A simple technique of securing inferior epigastric vessels and repairing the rectus sheath at laparoscopic surgery. Obstet Gynecol 90:304-306

19. Moran ME (1993) The management of laparocopic injuries of the bowel or blood vessels. Minim Invasive Ther Allied Tech 2:289291

20. Lewis JE (1995) A simple technique for anticipating and managing secondary puncture site haemorrhage during laparoscopic surgery. J Reprod Med 40:729-730

21. Levy B (2006) Vascular injuries. In: Isaacson K (ed) Gynecologic endoscopic surgery, 1st edn. Elsevier, Philadelphia, pp 73-78

22. Hurd WW, Amesse LS, Gruber JS et al (2003) Visualization of the epigastric vessels and bladder before laparoscopic trocar placement. Fertil Steril 80:209-212

23. Nezhat C (2005) Laparoscopic abdominal access. In: Wetter PA et al (eds) Prevention and management of laparoendoscopic surgical complications, 2nd edn. Society of Laparoendoscopic Surgeons, Miami 